\title{
Fuzzy logic controller for closed loop cascaded flyback converter fed PMDC-motor system
}

\author{
C.T. Manikandan, G.T. Sundarrajan \\ Department of Electrical and Electronics Engineering, Sathyabama Institute of Science and Technology, India
}

\begin{tabular}{l} 
Article Info \\
\hline Article history: \\
Received Feb 23, 2020 \\
Revised Apr 26, 2020 \\
Accepted May 19, 2020 \\
\hline
\end{tabular}

\section{Keywords:}

Fly back Converter Fuzzy logic control. PI controller Stability Analysis Total Harmonic Distortion (THD)

\section{Corresponding Author:}

CT. Manikandan, Departement of Electrical and Electronics Engineering, Sathyabama Institute of Science and Technology, Chennai, India. Email: manikandanct@yahoo.com

\begin{abstract}
This paper displays a Fly Back Converter idea to straightforwardly incorporate cascaded flyback converter. The flyback-converter finds a way between DC-source and DC Motor-load. This work covenants with the modeling, simulation, and application of a Fuzzy Logic controlled (FLC) Cascaded Fly back Converter (CFLB) system. This work recommends FLC to control Parallel cascaded fly-back converter to fabricate essential DC voltage from the input supply voltage. The yield of CFLB is controlled utilizing closed loop configuration. Closed loop PI \& Fuzzy logic controlled CFLB systems are simulated and their results are related. The outcomes signify that the FLC based system gave a superior response than the P.I. controlled CFLB system. The FLC controlled CFLB system has benefits like decreased steady state error and enhanced time domain-response.
\end{abstract}

This is an open access article under the $\underline{C C B Y-S A}$ license.

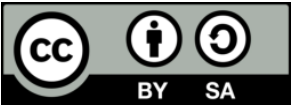

\section{INTRODUCTION}

Flyback converters were utilized for low force, high voltage applications on account of its straightforwardness, disconnection and short out insurance. The flyback converter encouraged both advance up \&step down the information voltage, while keeping up a similar ground reference and extremity for info and yield.

"A solitary switch ac-dc light emitting diode (LED) driver dependent on support flyback Power Factor Correction (PFC) converter with a lossless snubber" was presented [1]. In the proposed LED driver, the boost-PFC module was intended to be worked in the discontinuous conduction mode to accomplish a powerful factor. The dc-dc flyback module was intended to give input yield electrical seclusion to improve wellbeing. The lossless Snubber circuit braced the pinnacle voltage spike of change to a low voltage and the spillage inductor energy was reused through the dc-dc flyback module.

Displaying and examination of transformer less high increase buck-boost dc-dc converters was exhibited by $\mathrm{Vu}$ [2]. This paper proposed a transformer-less exchanged capacitor BBC model, which gives higher voltage gain and higher efficiency when contrasted with the customary BBC. The found the middle value of model dependent on state-space depiction was examined. Buck boost control of 4quadrant chopper utilizing balanced impedance arrange for flexible speed drive was recommended by Dash [3].

The traditional ICE represented an incredible risk to condition because of increment in tail pipe discharge. This was the principle reason that car industry is moving to greater condition agreeable and financially savvy advances and one such innovation was HEV which may fulfill electric force need, vehicle execution, and higher traveler comfort alongside expanded safety [4]. The vehicular application had a few 
points of interest, for example, expanded proficiency, confinement, better voltage guideline and adaptability, controlling force quality to each different board, diminished weight and size [5-8].

"Topology of dc-dc converter in sun-based PV-relevance's" was given by Nizar [9]. Sunlight based energy assumed a significant job in sustainable power source generation frameworks since it was perfect, contamination free reasonable energy just as the expanding cost of power which causes high-development requests among utility clients. Creator exhibited Investigation on particular Flyback converter utilizing PI and FLC. High advance up proportion converters for low voltage high ebb and flow energy sources were these days the focal point of an escalated research action by the force gadgets network, on account of the expanding enthusiasm for sustainable power sources like those dependent on PV modules and fuel cells. The exploration on DC-DC power converters had involved enthusiasm for a considerable length of time since this kind of converter can be utilized in a wide scope of utilizations. The fundamental research was centered around expanding the converter voltage gain while acquiring a decent effectiveness and unwavering quality [10-13].

Voltage mode control of incorporated boost-arrangement parallel flyback for energy-storagerelevance's was proposed by Vijay [14]. The fundamental favorable position of this converter was high dependability, high force move productivity and venture up gain. Utilizing this topology current weight on switches was diminished because of parallel activity. "A modified step-up dc-dc flyback converter with active snubber for improved efficiency" was proposed [15]. Among the diverse DC-DC converters, the flyback topology was outstanding and broadly utilized. In this, a novel high productivity changed advance up DC-DC flyback converter was presented.

Creator presented novel control conspires for an Interleaved Flyback converter based sunlight based PV smaller scale inverter to accomplish high productivity. Moreover, it additionally lessens the conduction misfortunes through low current top due to BCM and equivalent current sharing between the two converters at the high influence level [16-19]. Exchanging misfortunes, because of the low recurrence activity of the $\mathrm{BCM}$ at a powerful level, are additionally decreased. Working mode choice of the interleaved inverter at a specific force level depends on the data of ideal proficiency. Definite computations of pinnacle current references have been completed for the different working methods of the interleaved flyback based micro-inverter.

Input-series \& yield arrangement associated measured solitay-switch flyback converter working in the irregular conduction mode was exhibited by Faust [20]. 'An elevated effectiveness flyback micro-inverter with another versatile snubber for PV-relevance's' was recommended by Lee [21]. An evaluation between different snubbers for flyback converters was presented [22-23]. Several studies [24-27] have suggested that the importance of power factor in power electronics applications and the improvement of power factor to be carried out periodically.In this work, the steady state activity of each snubber circuit was clarified in detail and broke down, the aftereffects of the investigation was utilized to make a strategy for the plan of key parts, and the technique was displayed with a structure model.

\section{RESEARCH GAP}

There is a need to improve the dynamic response of CLFB System. The above papers do not talk about enhancement of dynamic response of CLFB system using PI/FL controllers. The above literature does not deal with comparison of PI and FL controlled CL-CLFBS. This work suggests FLC for the control of CL-CLFBS.

\section{SYSTEM DESCRIPTION}

Block-diagram of Open Loop fly back converter system is exposed in Figure.1. The yield of PV is altered to DC utilizing Cascaded Flyback Inverter (CFI). The yield of CFI is rectified using controlled rectifier (CR). The yield of CR is applied to the DC Motor.

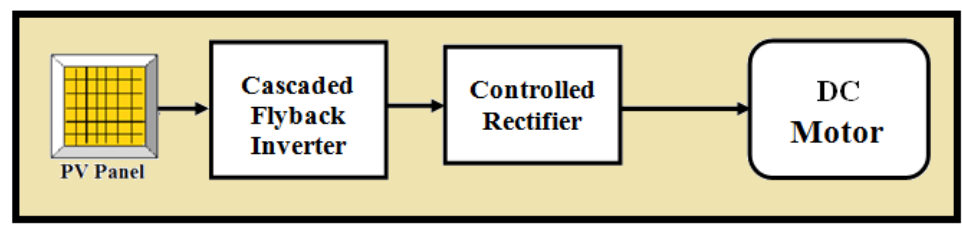

Figure 1. Block diagram of open loop CFBCS 
Block diagram of closed-Loop cascaded flyback converter system is exposed in Figure.2. The speed of PMDCM is related with a reference speed. The flaw is pragmatic to a PI/FL-controller. The-yield of comparator updates the PW applied to CR.

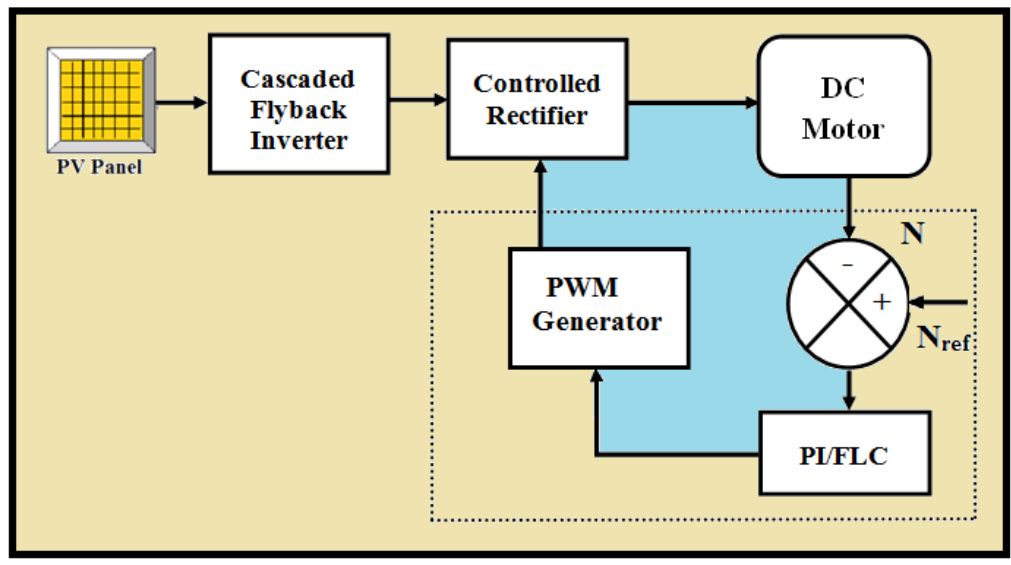

Figure 2. Block-diagram of closed-loop-CFBCS with PI and FLC controller

\section{SIMULATION RESULTS}

The Circuit obtained from Matlab Simulink environment is displayed below. 'Circuit-diagram ofCFBCS with-source disturbance' is appeared in Figure 3.

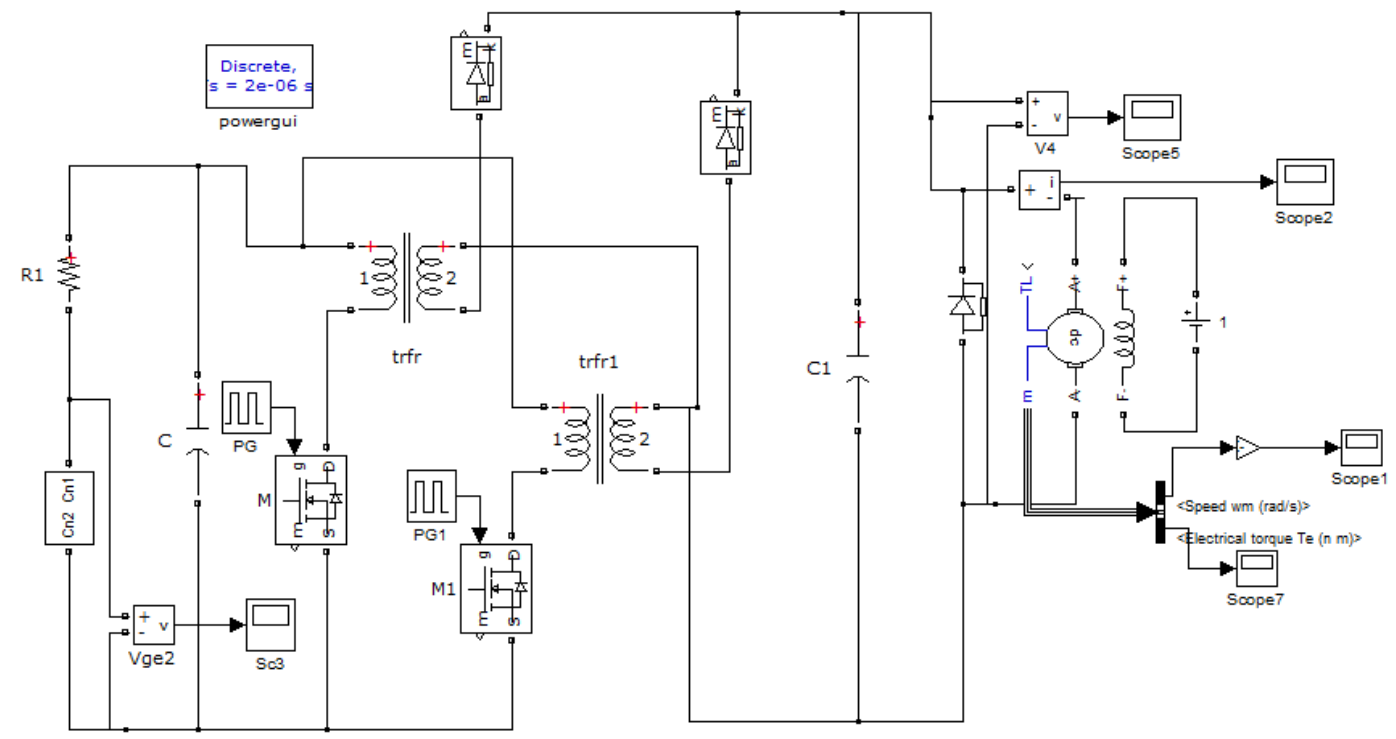

Figure 3. Circuit-diagram of CFBCS with source-disturbance

Input voltage of CFBCS is displayed in Figure 4 and its value rises from $48 \mathrm{~V}$ to 50 Volts. Voltage across motor load of CFBCS is appeared in Figure 5 and its value settles at 420 volts. Current through motor load of CFBCS is displayed in Figure 6 and its value is $8.5 \mathrm{Amp}$. Motor speed of CFBCS is delineated in Figure 7 and its value is 1400 RPM. Motor Torque response of CFBCS is appeared in Figure 8 and its value is $9.5 \mathrm{~N}-\mathrm{m}$.

Circuit diagram of-closed-loop-CFBCS with PI-controller is displayed in Figure 9. The speed of PMDCM is related with a set-speed. The flaw is pragmatic to a P.I.-controller. The-yield of comparator updates the PW applied to CR in the $2^{\text {ndary }}$ of CFBCS. 


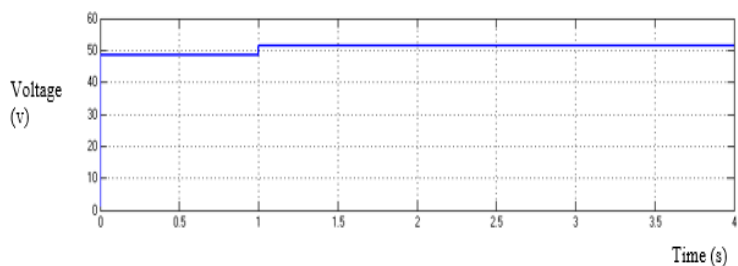

Figure 4. Input voltage of CFBCS

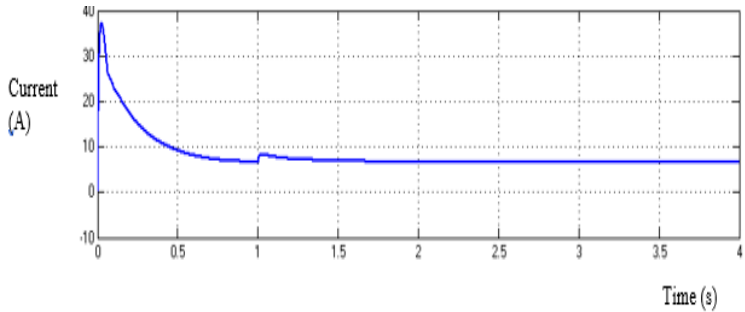

Figure 6. Current through motor load of CFBCS

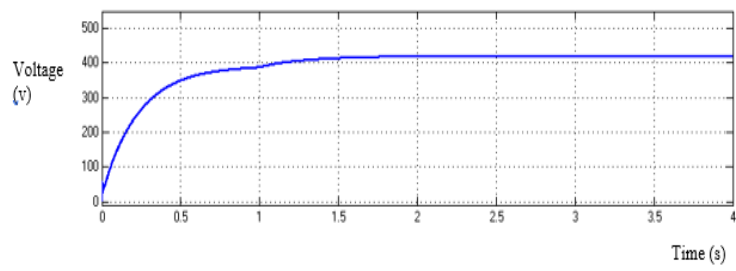

Figure 5. Voltage across motor load of CFBCS

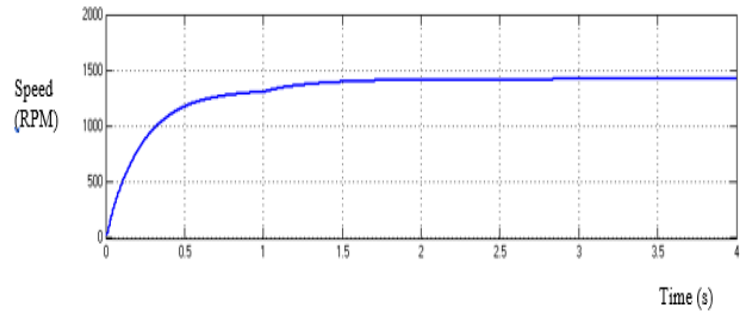

Figure 7. Motor speed of CFBCS

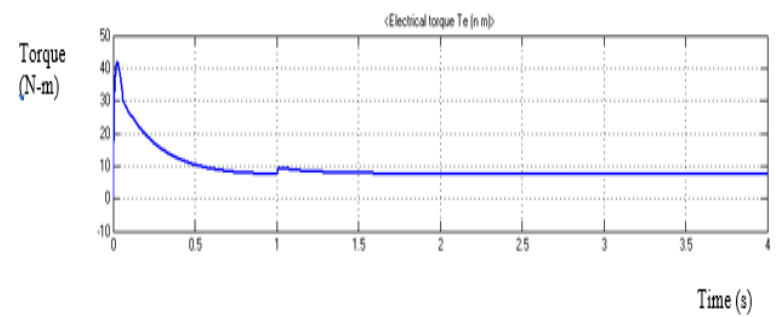

Figure 8. Motor torque of CFBCS

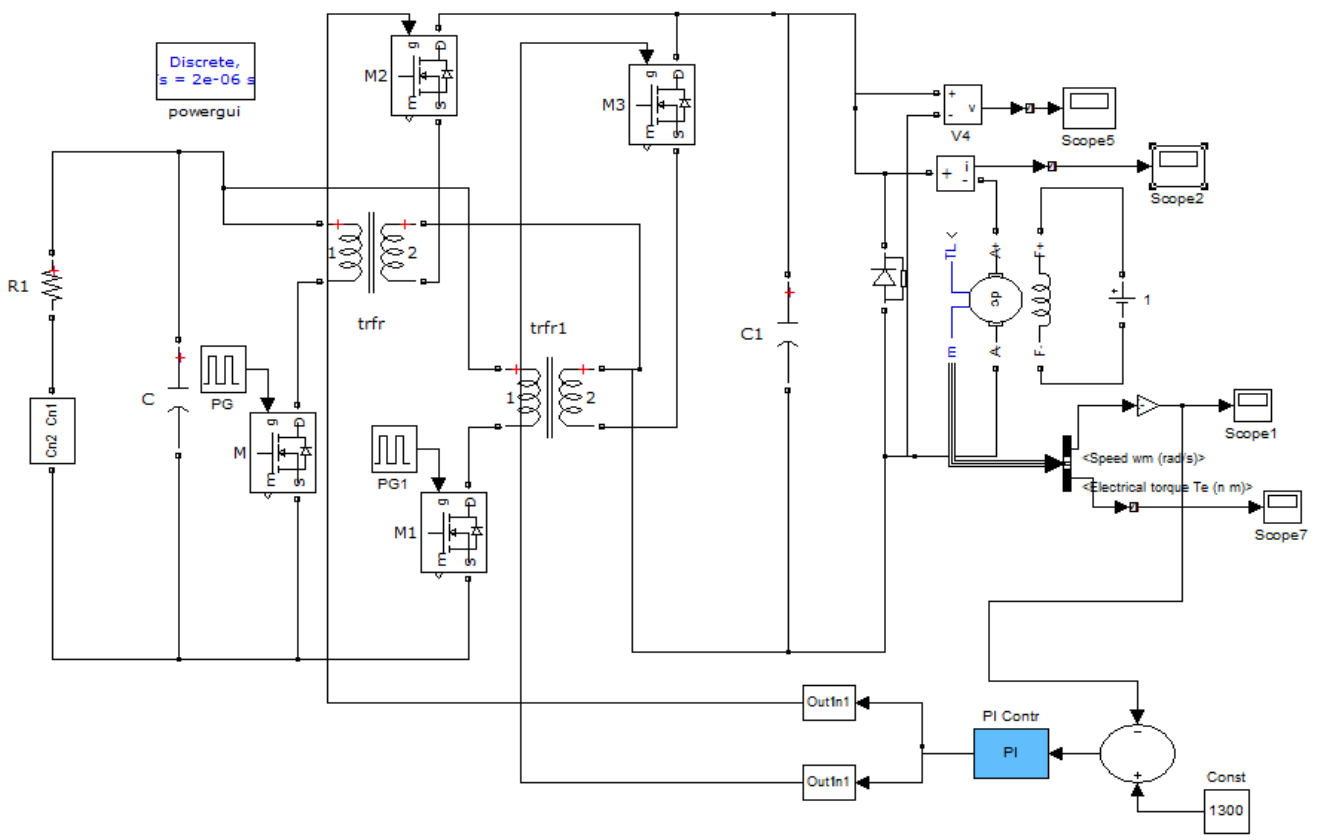

Figure 9. Circuit diagram of closed loop CFBCS with PI controller 
Input voltage of CL-PI-CFBCS is displayed in Figure 10 and its value is 50 Volts. Voltage across motor load of CL-PI-CFBCS is displayed in Figure 11 and is value is 400 volts. Current through motor load of CL-PI-CFBCS is delineated in Figure 12 and its value is 8.5 Amp. Motor speed of CL-PI-CFBCS is displayed in Figure 13 and its value is 1250 RPM. Motor Torque of CL-PI-CFBCS response is displayed in Figure 14 and its value is $9.8 \mathrm{~N}-\mathrm{m}$.

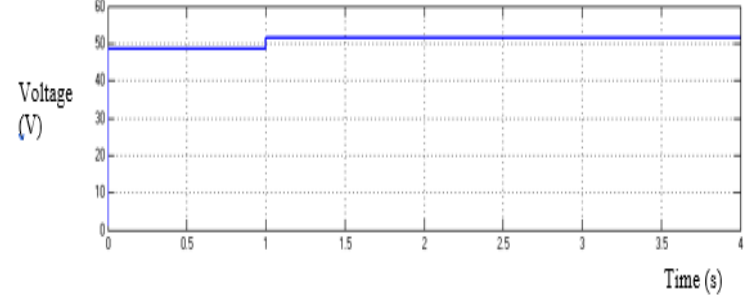

Figure 10. Input voltage of CL-PI-CFBCS

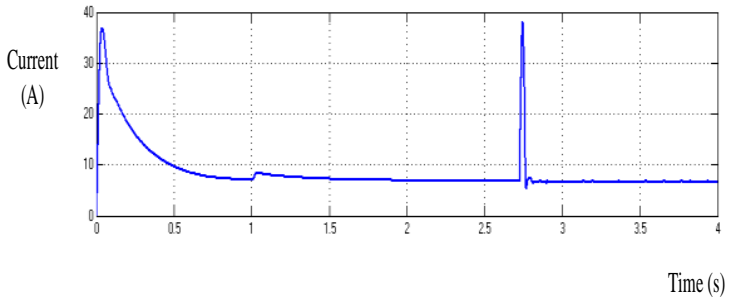

Figure 12. Current through motor load of CL-PICFBCS

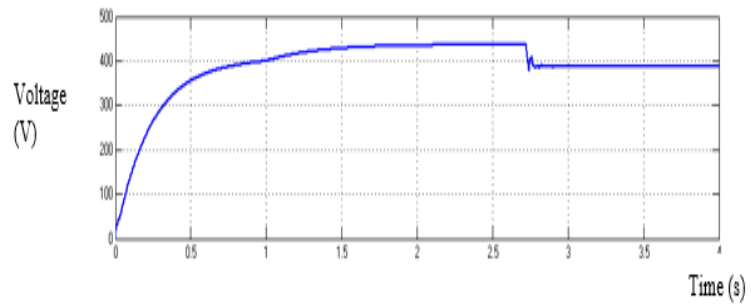

Figure 11. Voltage across motor load of CL-PICFBCS

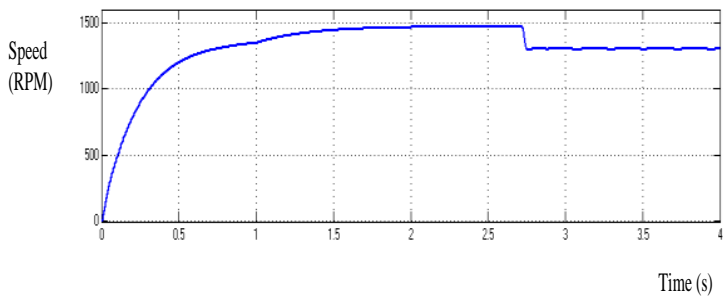

Figure 13. Motor speed of CL-PI-CFBCS

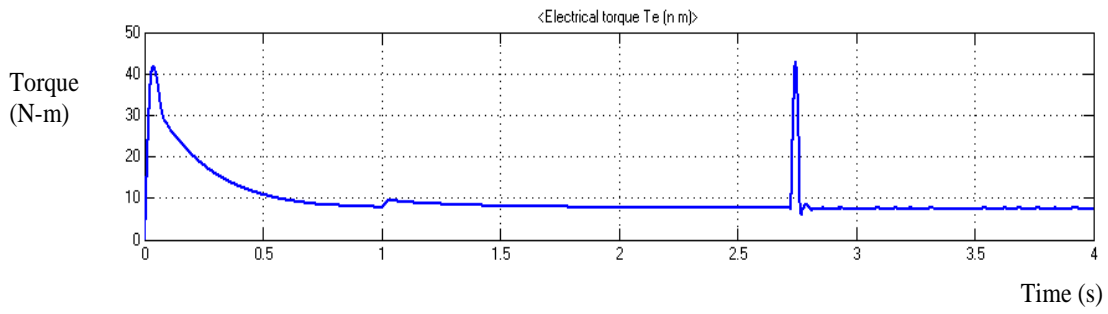

Figure 14. Motor torque of CL-PI-CFBCS

Circuit diagram of closed-loop-CFBCS with FL controller is displayed in Figure 15. A Fuzzycontroller substitutes the PI-controller in the preceding system. The speed of PMDCM is related with wantedspeed. The flaw is pragmatic to a FL controller. The yields of 2 comparators update the pulse width applied to $\mathrm{CR}$ in the secondaries of CFBCS.

Input voltage of CL-FL-CFBCS is displayed in Figure 16 and its value is 55 Volts. Voltage across motor load of CL-FL-CFBCS is displayed in Figure 17 and is value is 400 volts. Current through motor load of CL-FL-CFBCS is delineated in Figure 18 and its value is $8.5 \mathrm{Amp}$. Motor speed of CL-FL-CFBCS is displayed in Figure 19 and its value reaches 1250 RPM without any oscillations. Motor Torque of CL-FLCFBCS response is displayed in Figure 20 and its value is $9.8 \mathrm{~N}-\mathrm{m}$. 


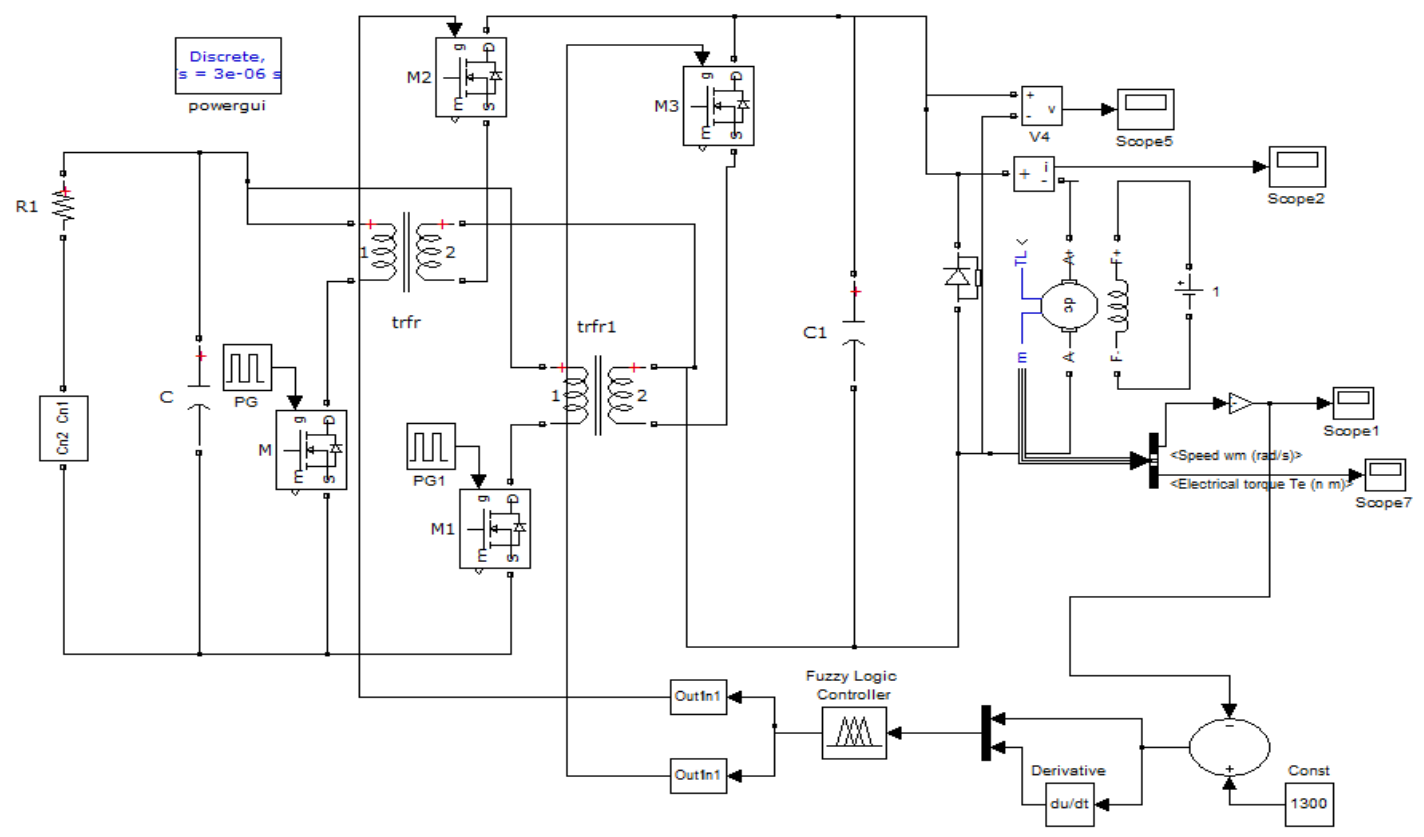

Figure 15. Circuit diagram of closed loop CFBCS with FL controller

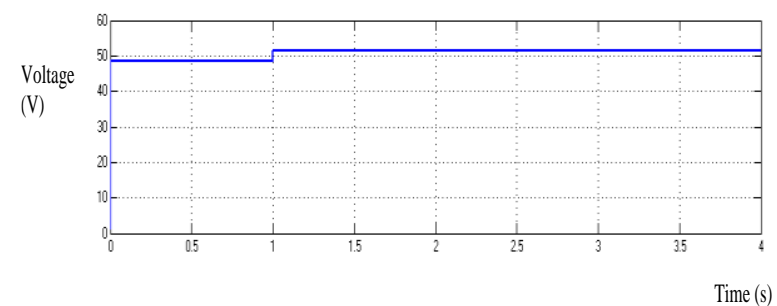

Figure16. Input voltage of CL-FL-CFBCS

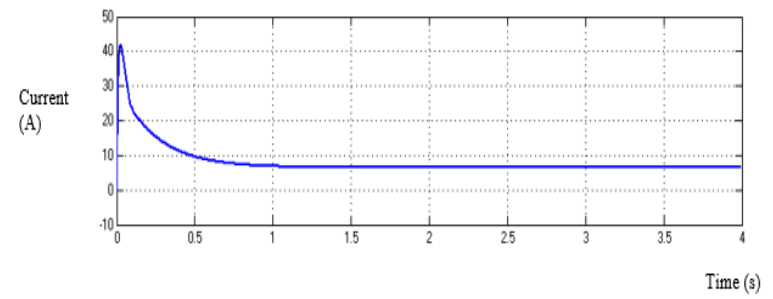

Figure 18. Current through motor load of CL-FLCFBCS

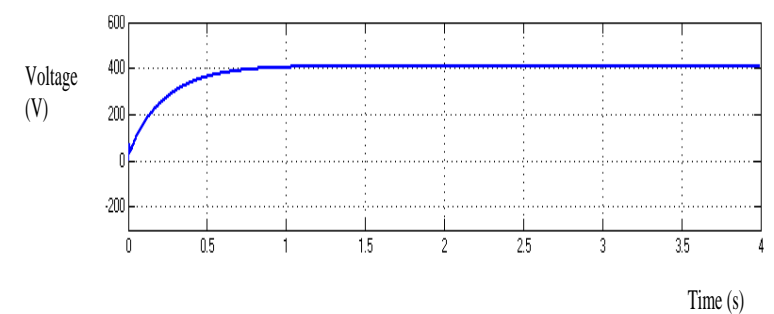

Figure 17. Voltage across motor load of CL-FLCFBCS

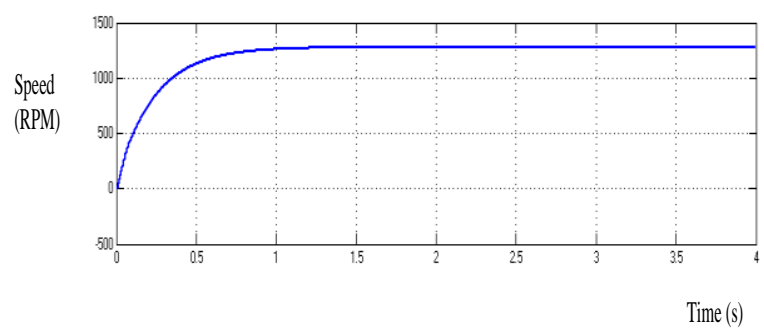

Figure 19. Motor speed of CL-FL-CFBCS

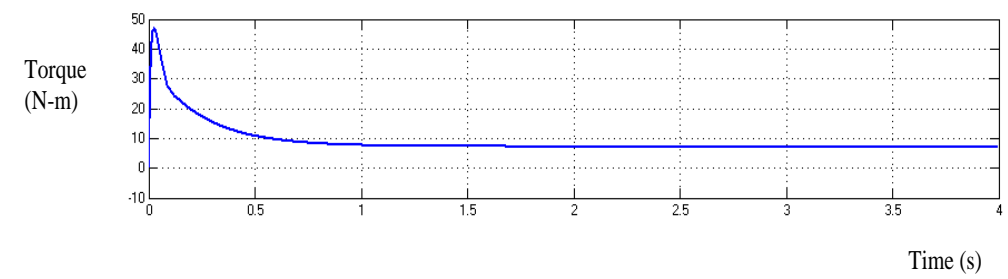

Figure 20. Motor torque of CL-FL-CFBCS 
Comparison of time domain parameters based CFBCS using PI and FL controller are given in Table 1. By using-FLC, the-rise-time is reduced from $1.65 \mathrm{Sec}$ to $0.85 \mathrm{Sec}$; the-peak-time is reduced from 2.66 Sec to $1.50 \mathrm{Sec}$; the-settling-time is reduced from $2.76 \mathrm{Sec}$ to $1.82 \mathrm{Sec}$; the-steady-state-error is reduced from $3.3 \mathrm{~V}$ to $0.9 \mathrm{~V}$. 'Bar chart-comparison of-time-domain-parameters' is displayed in Figure 21.

Table 1. Comparison of time domain parameters based CFBC systems

\begin{tabular}{ccccc}
\hline Controller & $\mathrm{T}_{\mathrm{r}(\mathrm{Sec})}$ & $\mathrm{T}_{\mathrm{p}(\mathrm{Sec})}$ & $\mathrm{T}_{\mathrm{s}(\mathrm{Sec})}$ & Ess \\
\hline PI & 1.65 & 2.66 & 2.76 & 3.3 \\
FLC & 0.85 & 1.50 & 1.82 & 0.9 \\
\hline
\end{tabular}

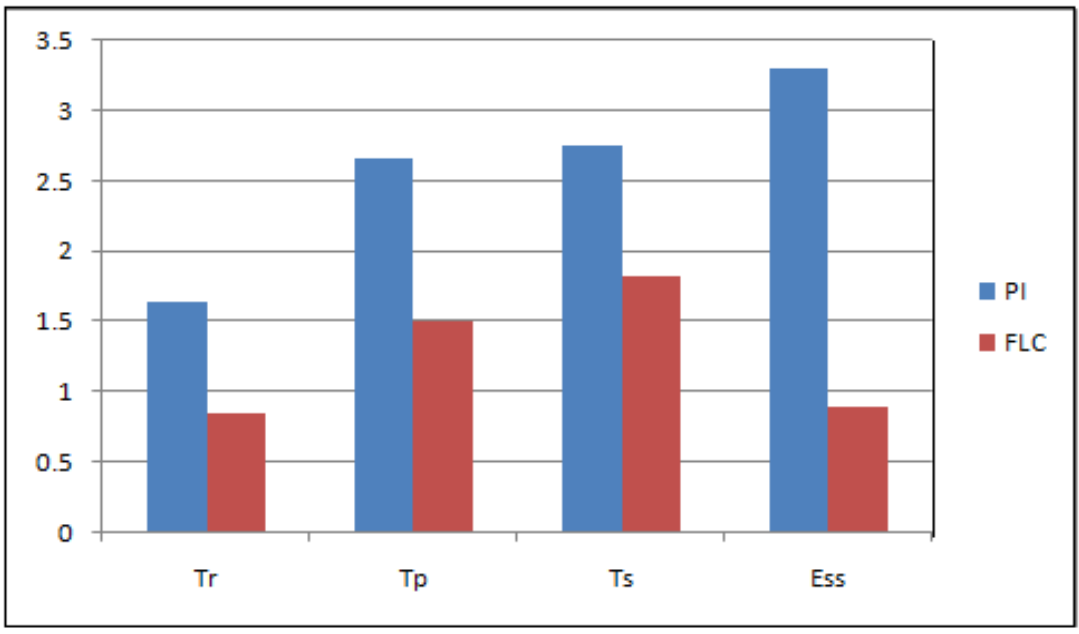

Figure 21. Bar chart comparison of time domain parameters

\section{CONCLUSION}

This work deals with Closed-loop PI \& Fuzzy logic controlled CFLB systems. The speed of CFLBS is regulated using closed loop configuration. Closed loop PI \& Fuzzy logic controlled CFLB systems are simulated. The response of fuzzy logic control CL-CFBCS is compared with conventional ProportionalIntegral (PI) controlled in a CL-CFBCS. The FLC has minimum overshoot \&produces constant yield current $\&$ voltages. In the case of output voltage same changes obtained. From these data it can be infer that the settling time is reduced from the range of 2.76 seconds to 1.82 seconds, which would improve the stability of the system with fuzzy logic controller platform than a PI controller platform.

Contribution of this work is to improve dynamic response of the CFLB with feedback system. Proposed CFLB system has advantages like high power capability and improved time domain response. The requirement of 2transformers and 4MOSFETs is the drawback of proposed CFLB system. The SMC based CFLB system will be simulated in future

\section{REFERENCES}

[1] S.W. Lee, H.L. Do, "A Single-Switch AC-DC LED Driver Based on a Boost-Flyback PFC Converter with Lossless Snubber," IEEE Transaction on Power Electronics, vol. 32, no. 2, pp. 1375-1384, 2017.

[2] Vu Tran, MufeedMah D, "Modeling and Analysis of Transformer less High Gain Buck-boost DC-DC Converters", International Journal of Power Electronics and Drive Systems, vol 4, no 4, pp. 528-537, 2014.

[3] SaswatiSwapna Dash and ByamakeshNayak, "Buck-Boost Control of Four Quadrant Chopper using Symmetrical Impedance Network for Adjustable Speed Drive”, International Journal of Power Electronics and Drive Systems, pp. 424-432, 2014.

[4] Atul Kumar and Prerna Gaur, "Operation of DC/DC Converter for Hybrid Electric Vehicle", International Journal of Electronic and Electrical Engineering, ISSN 0974-2174, vol 7, no 4 (2014), pp. 335-340.

[5] NooriBawi Dawood, "Review of Different DC to DC Converters Based for Renewable Energy Applications", International Research Journal of Engineering and Technology, e-ISSN: 2395 -0056, vol 03 Issue: 03 | Mar-2016 www.irjet.net p-ISSN: 2395-0072. 
[6] OzwinDominc Dsouza, ManjunathaBabu P, BabuNaik G, Shilpa G, "7.5W Current Mode Control of Isolated Flyback Converter", International Journal of Informative \& Futuristic Research (IJIFR), vol - 3, Issue -7, Mar 2016, Continuous 31st Edition, pp:2634-2648, ISSN: 2347-169.

[7] Nisha Kasundra, Ankit Kumar, "Design and Simulation of Flyback Converter in MATLAB using PID Controller", International Journal of Advanced Research in Electrical, Electronics and Instrumentation Engineering, Vol. 5, Issue 2, Feb 2016.

[8] MediPallavi, S.L. V Sravan Kumar, N. Ravishankar Reddy, "Integrated Boost Parallel Flyback Converter for Multi Load Applications", International Journal of Innovative Technology and Exploring Engineering (IJITEE) ISSN: 2278-3075, vol-8, Mar 2019.

[9] Nor HanisahBaharudin, Tunku Muhammad Nizar Tunku Mansur, Fariruz Abdul Hamid, Rosnazri Ali, Muhammad Irwanto Misrun, "Topology of DC-DC Converter in Solar PV Applications", Indonesian Journal of Electrical Engineering and computer Science, vol.8, no.2, Nov 2017.

[10] V.Jaikrishna, Subranhsusekhar Dash, LinssTAlex \& R. Sridhar,"Investigation on modular Fly-back converter using PI and Fuzzy Logic Controllers", International Journal of Ambient Energy, pp 1-10, Jun 2017

[11] G. Spiazzi, P. Mattavelli, J. R Gazoli, R. Magalhaes, G. Frattini. "Improved Integrated Boost-Flyback High Step up Converter", 2010 IEEE International Conference on Industrial Technology.

[12] GurkanTosun, Omer CihanKivanc, EnderOgux, OzgurUstun and R. NejatTuncay. "Development of high efficiency multi-output Flyback Converter for Industrial Applications", $9^{\text {th }}$ International Conference on Electrical and Electronics Engineering (ELECO),2015

[13] S.L.V Sravan Kumar, Dr. N. Ravishankar Reddy, Dr. M. Vijay Kumar, "Quasi switched capacitor integrated boost series parallel fly-back converter for energy storage applications," Journal of advanced research in dynamical and control systems, vol. 9. 2017.

[14] Sravan Kumar S.L.V, RaviSankar Reddy. N, Vijay Kumar. M," Voltage Mode Control of Integrated Boost Series Parallel Fly-Backter for Energy Storage Applications", $1^{\text {st }}$ international conference on power engineering computing and control PECCON-2017,2-4 Mar 2017, VIT University, Chennai Campus.

[15] Cristian Pesce, Javier Riedemann, Ruben Pena, Werner Jara, Camilo Maury and Rodrigo Villalobos, "A Modified Step-Up DC-DC Flyback Converter with Active Snubber for Improved Efficiency”, Energies 2019, 12, 2066; doi:10.3390/en12112066.

[16] Lodh.T, Pragallapati.N, Agarwal.V, "Novel Control Scheme for an Interleaved Flyback Converter Based Solar PV Micro inverter to Achieve High Efficiency", IEEE Transactions on Indusrial Applications, pp 3473-3482, 2018.

[17] Shen. C, Chiu. P, "Buck-boost-flyback integrated converter with single switch to achieve high voltage gain for PV or fuel-cell applications", IET Power Electronics, vol.9, pp 1228-1237, 2016.

[18] Cheng.H, Chang.Y, Chang.C, Hsieh.S, Cheng.C, "A Novel High-Power-Factor AC/DC LED Driver with Dual Flyback Converters", IEEE Journal of Emerging and Selected Topics in Power Electronics, vol 7, pp 555-564, 2019.

[19] Tseng.S. Y, Huang.P.J.Wu.D.H, "Power Factor Corrector with Bridgeless Flyback Converter for DC Loads Applications", vol 11, Energies 2018.

[20] Pagliosa.M, Faust.R, Lazzarin.T, Barbi.I, "Input-series and output-series connected modular single-switch flyback converter operating in the discontinuous conduction mode", IET Power Electronics, vol 9, pp 1962-1970,2016.

[21] Rezaei.M, Lee.K, Huang, A, "A High-Efficiency Flyback Micro-inverter With a New Adaptive Snubber for Photovoltaic Applications", IEEE Transactions on Power Electronics, vol 31, pp 318-327,2016.

[22] Dong. M, Tian. X, Li. L, Song. D, Wang. L, Zhao. M, "Model-Based Current Sharing Approach for DCM Interleaved Flyback Micro-Inverter", vol 11, Energies 2018.

[23] Alganidi, A, "A Comparison between Different Snubbers for Flyback Converters", Master's Thesis, The University of Western Ontario, London, ON, Canada, 2017. Available online: https://ir.lib.uwo.ca/etd/5153 (accessed on 22 May 2019).

[24] V. SenthilNayagam, G. T. SundarRajan and V. Balasubramanian, "Improved Power Factor at Input Stage of Pseudoboost Rectifier with Improved Switching Pattern”, International Journal of Applied Engineering Research, vol 10, no 6, 2015, pp. 5158 - 5164. ISSN 0973-4562.

[25] R. Hemaprithni and G.T. SundarRajan, "Three Level Integrated AC to DC Converter fed DC Drive with Cascaded filter", International Journal of Applied Engineering Research, vol 10, no 6, 2015, pp. 5140 - 5146. ISSN 09734562 .

[26] G. T. SundarRajan, "Power Quality Improvement at Input and Output Stages of Three Phase Diode Rectifier using Artificial Intelligent Techniques for DC and AC Drive Applications", IEEE International Conference on Computational Intelligence and Computing Research (ICCIC - 2014), PARK College of Engineering and Tekhnology, Coimbatore, Tamilnadu, INDIA, pp. 904 - 909, Dec 18 to 20,2014.

[27] D. Jayanthy, G.T. SundarRajan, "A Novel Unity Power Factor at Input Stage of Vienna Rectifier for Wind Energy Conversion System Using Fuzzy Logic", International Journal of Applied Engineering Research, vol 10, no 6, 2015 , pp. 5650 - 5655. ISSN 0973-4562. 


\section{BIOGRAPHIES OF AUTHORS}

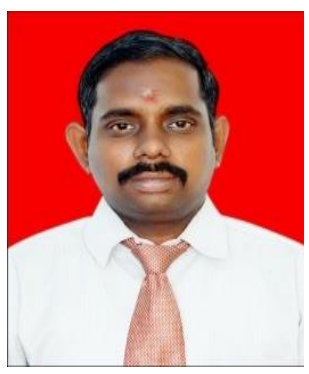

C.T.Manikandan completed B.E. at VRS college of Engg \&Tech affiliated to Anna University in 2005 and ME at CEG campus,Anna University in 2009 and undergoing $\mathrm{PhD}$ at Sathyabama Institute of Science and Technology.He has published few papers in national and international journals and confernces.Presently he is working as Associate Professor in the Department of EEE at Panimalar Institute of Technology,Chennai.He has a total teaching experience of 11 years.His areas of interest are Electrical Machines, Electromgnetic theory ,Power Electronics \& Drives and Power Systems.

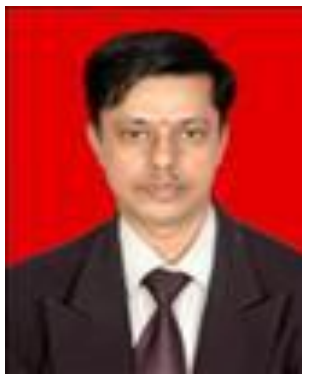

G. T. Sundar Rajan born in Tirunelveli District, Tamilnadu State, India in 1975, received B.E. degree in Electrical and Electronics Engineering from the University of Madras and the M.E. degree in Power Electronics and Industrial Drives and $\mathrm{Ph}$. D. from the Sathyabama University, Chennai, India in 1997, 2007 and 2014 respectively. He has published few technical papers in international and national journals and conferences. Presently he is working as an Associate Professor in the Department of EEE at Sathyabama Institute of Science and Tchnology, Chennai. He has a total teaching experience of 14 years. His areas of interest are power quality improvement, harmonics reduction, AC and DC drives. 